\title{
Use of electrical imaging in site investigations for a railway tunnel through the Hallandsås Horst, Sweden
}

\author{
Torleif Dahlin, Leif Bjelm \& Conny Svensson
}

Department of Geotechnology, Lund University, Box 118, S-221 00 Lund, Sweden

\begin{abstract}
Investigations over two major tectonic zones in the Hallandsås Horst, Southern Sweden were carried out in connection with a railway tunnelling project. A combination of resistivity imaging, core drilling and geophysical logging was found to provide a good overview of the variation in rock quality and detailed information on the engineering geological characteristics and genesis of the strata. Resistivity data, acquired along parallel lines over the zones using multi-electrode equipment, were processed by means of automatic inversion software to generate sections showing the variation of resistivity with depth. Wireline core drilling at selected points gave an almost complete core recovery, which revealed major sedimentary sequences and heavily weathered crystalline rocks that were previously unknown or only partially known despite conventional core drilling and percussion drilling. Geophysical borehole logging confirms the resistivity imaging results, and would be a particularly valuable complement to core logging in cases where significant core loss occurs.
\end{abstract}

Keywords: drilling, geophysics, site investigation, resistivity, tunnels

\section{Introduction}

The Hallandsås Railway Tunnel Project is one of the largest construction works in Sweden today. Two parallel tunnels of $62 \mathrm{~m}^{2}$ cross section are to be constructed, each $8.6 \mathrm{~km}$ long. However, rock quality problems have made it necessary to abandon the full-face boring (TBM) technique used in 1993, and revert to conventional tunnelling methods. This change in approach necessitated measurement of rock quality at certain key points along the planned tunnel route.

This paper presents composite investigations of the Southern Marginal Zone of the Hallandsås Horst, a zone which crosses the planned tunnel route approximately $1 \mathrm{~km}$ north of the southern tunnel entrance and where severe rock quality problems can be expected. The composite site investigation includes a surface resistivity survey combined with wireline core drilling and borehole resistivity logging. Results are also presented for the Möllebäcken Zone, which crosses the tunnel line a few kilometres further north; however, here the resistivity results are supported by conventional drilling.

\section{Regional geology and rock engineering concepts}

The Hallandsås Horst (Fig. 1) is one of several uplifted blocks of the Earth's upper crust that are found in Skåne, the southernmost province of Sweden. The horst, composed of Precambrian rocks, is flanked by younger sedimentary rocks and is $8-10 \mathrm{~km}$ wide, $30-40 \mathrm{~km}$ long and trends NW-SE (Fig. 2). The horst reaches an elevation of $150-200 \mathrm{~m}$ in the tunnel area with a steep northerly slope and a more gentle slope on the southern side.

It is expected that the Hallandsås Horst consists of crystalline and fine-grained metamorphic rocks of the Precambrian gneiss complex of Southwest Sweden. In the tunnel area there is gneiss with amphibolitic parts and several generations of NW-SE-trending dolerite dykes, connected to several generations of tectonic movement. The dykes which cross the tunnel and the joint system in the tunnel area are rock mass discontinuities of hydrogeological importance. Further west on the Hallandsås Horst quite a few relatively high-yielding

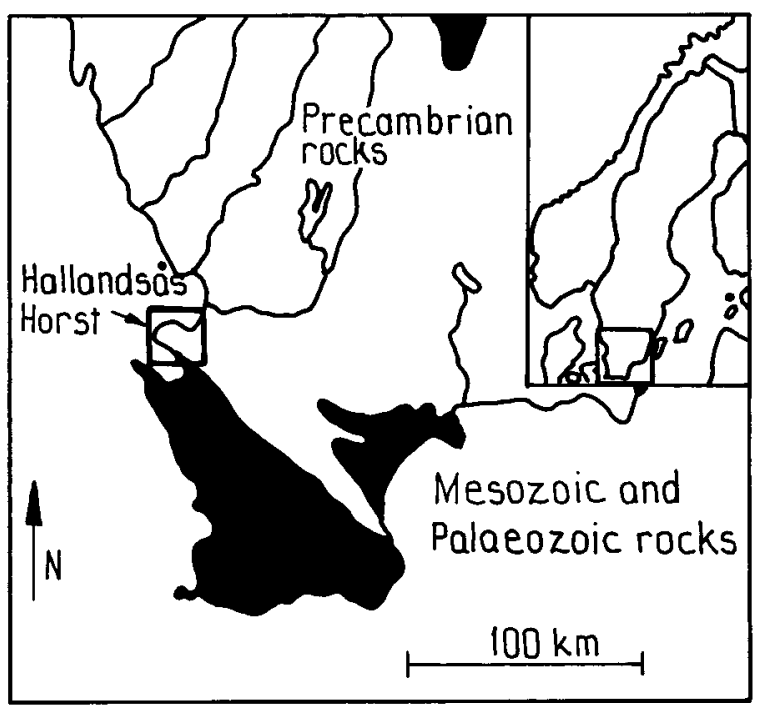

Fig. 1. Regional geological overview map of Scania (after Wikman \& Bergström 1987a). 


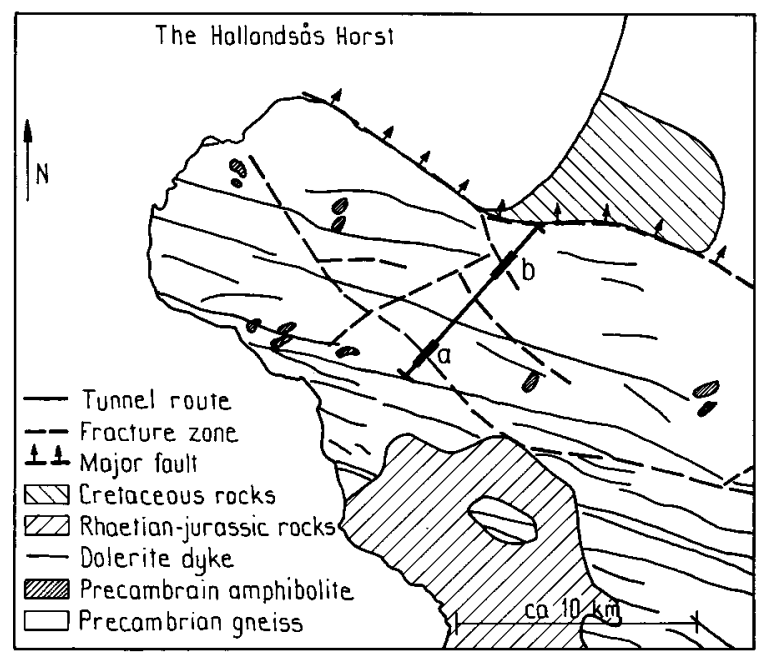

Fig. 2. Geological map over the Hallandsås Horst with tunnel line indicated (after Wikman \& Bergström 1987a). The positions of the investigated lines are indicated by (a) for the Southern Marginal Zone and (b) for the Möllebäcken Zone.

water wells were drilled in the gneiss during the 1980s. Furthermore, because Pleistocene glaciations have eroded the regolith of former geological periods, the degree of weathering in the Swedish Precambrian rocks is generally very low, although there are exceptions as will be shown in this paper. (Wikman \& Bergström 1987a,b).

As shown in Fig. 2, the entire tunnel will be constructed in rock mapped as gneiss. However, sedimentary rocks do exist just outside the tunnel area both north and south of the tunnel. Drilling carried out as part of this investigation and presented below adds new geological data on sedimentary rocks in this area.

From a geological point of view one can assume that construction problems will arise along the NW-SE trending faults which form the northern and southern borders of the Hallandsås Horst. These major faults originated some 500 million years ago and could, in reality, form zones several hundred metres wide with fractures, crushed rocks, mineralization and clay weathering, which can give rise to water problems and structural problems during tunnel construction.

\section{DC resistivity surveying}

DC resistivity surveying has been used since $c .1910$, but developments in recent years have increased the practical applicability of the method. The resistivity of natural rock varies within wide ranges, and is essentially dependent on water content and the degree of weathering in rocks since the most common rock forming minerals are insulators. Thus, unweathered crystalline rocks have high resistivities, while rocks containing water bearing fractures and weathered zones have significantly lower resistivities. The resistivity of sedimentary rock depends on the character of the sediments, i.e. porosity, ion content of the pore water, degree of cementation, clay content, etc. (e.g. Parasnis 1986; Palacky 1987).

Measurements of ground resistivity are made by passing a controlled current between two electrodes, while measuring the potential across two other electrodes (Kunetz 1966; Parasnis 1986; Ward 1989). By systematically increasing the spacing between the electrodes the variation of resistivity with depth can be assessed, and by moving the position of the electrode array along a line the lateral variation can be mapped. Although manual data acquisition is laborious, the advent of computer controlled multi-electrode systems has augmented the productivity in field data acquisition tremendously (e.g. Overmeeren \& Ritsema 1988; Griffiths et al. 1990; Dahlin 1993), and it is now possible to acquire large data sets quickly. Together with improved inverse numerical modelling it is possible to interpret data from areas of complex geology quickly and efficiently.

\section{Data acquisition}

Field measurements were carried out along five parallel lines separated by 25 metres over each zone. Over the Southern Marginal Zone the profiles covered 900 metres or 1 kilometre from the first to the last instrument station, while the Möllebäcken Zone the profiles cover 600 metres. The fieldwork was carried out by two people in ten and five working days respectively. The terrain exhibits a mixture of agricultural land and occasionally dense forest. A few buildings are passed by the traverse lines, as well as an electric railway, all of which are potential sources of electric noise.

The ABEM Lund Imaging System was used for data acquisition in this study. The system consists of a resistivity meter (Terrameter SAS300C), a $4 \times 64$ channel relay-matrix switching unit (Electrode Selector ES464), four electrode cables (each with 21 take-outs), a portable PC, steel electrodes and various connectors etc. (Fig. 3). Cables with 5 metre take-out spacings were used, which gave 400 metres layout in total with four electrode cables linked together. A separate current amplifier (Booster SAS2000) was used to ensure a good signal-to-noise ratio, which allowed injection of $50 \mathrm{~mA}$ current or more in this environment.

The data acquisition process is completely controlled by the computer software, which checks that all the electrodes are connected and properly grounded before measurement starts. After adequate grounding is attained the software runs according to the measurement protocol selected by the user.

Wenner CVES (continuous vertical electrical sounding) was used in this survey, where the measurements at 


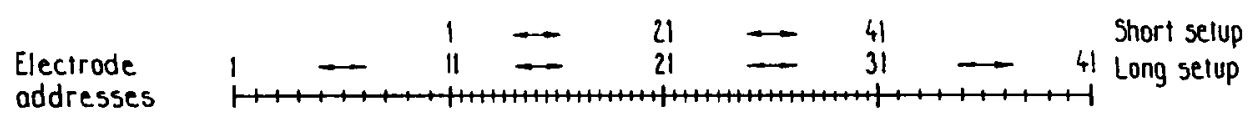

Cable
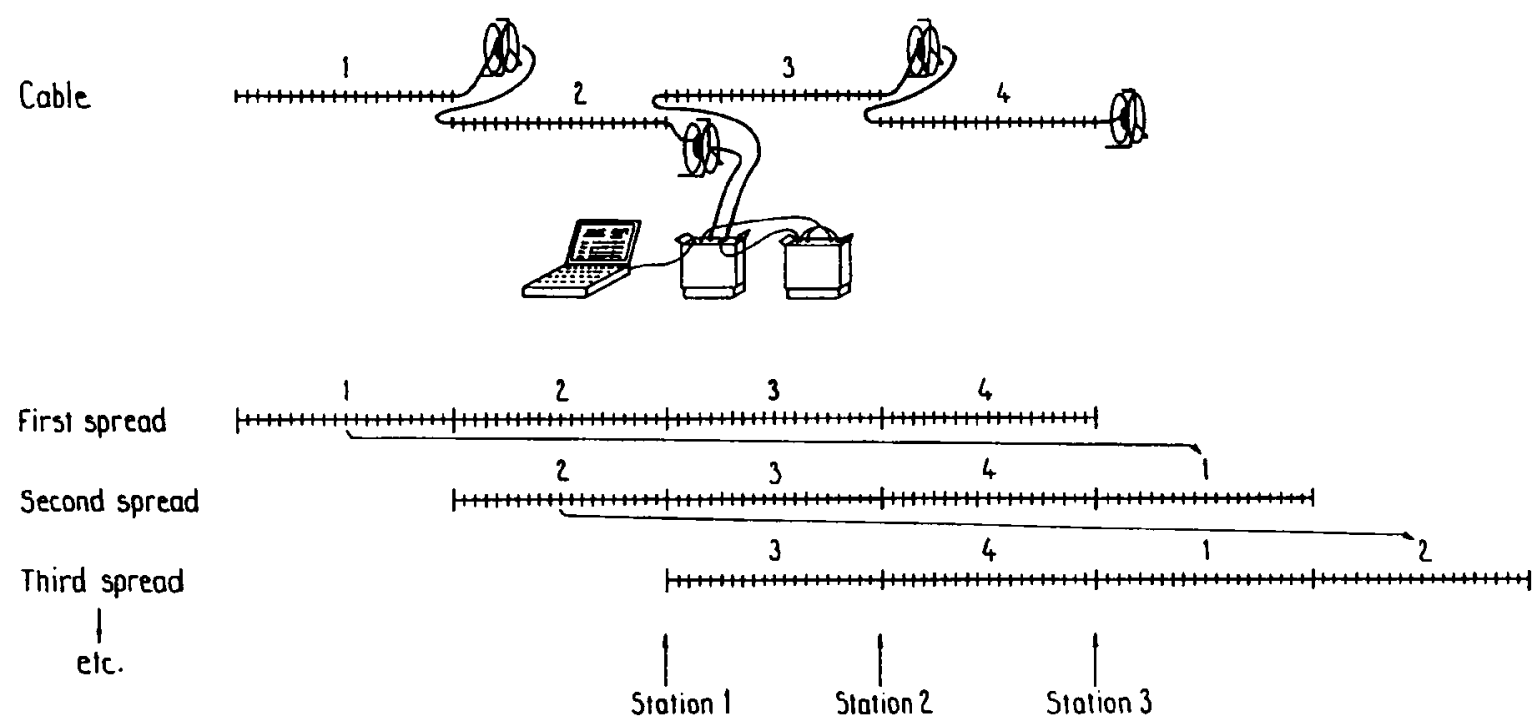

Fig. 3. Sketch outline of computer-controlled data collection system, were each mark on the cables indicates an electrode position. The figure also shows the principle of moving cables when using the roll-along technique. The total layout length was 400 metres for the data presented here (modified from Overmeeren \& Ritsema 1988).

each instrument station are divided into two parts. The first part involves all four electrode cables, and uses every second electrode take-out. These electrode takeouts are colour coded to facilitate field work. A measurement procedure is used which allows roll-along of cables and electrodes while measuring is in progress (Dahlin 1993, 1996). When the measurements involving cable one and four are finished, the procedure commences using only the two central cables. In the meantime cable one can be disconnected and moved to the far end of the layout (Fig. 3), and electrodes installed while measuring is still in progress. After measuring is complete at the first mid-point, the instrument is moved and measuring continues at the new mid-point with every second or fourth electrode active. The electrodes that are not active on cable one (former cable two) can be moved to the new cable three, to be in place when measuring involving only the two central cables starts.

The measurement protocol used for the data presented here provides Wenner CVES with ten different spacings ranging between 5 and 120 metres.

\section{Data processing interpretation}

Automatic pseudosection plotting in greyscales or colour was used in the field for data quality control and for initial interpretation of the data. A pseudosection is constructed by contouring the measured apparent resistivities, where the midpoint between the electrodes is used for length scale and the electrode separation for depth scale. The use of linear interpolation for the pseudosection plotting means that the data are not smoothed, and the quality of the data can be assessed.

A model of the true resistivity structure was interpreted using 2D smoothness constrained inversion. In the inversion, two-dimensional (2D) structures are assumed, i.e. the properties are constant perpendicular to the line of the profile, although the current electrodes are modelled as 3D sources. A finite difference (FD) model of the resistivity distribution in the ground is generated and adjusted to fit the data iteratively using a least squares technique. The smoothness constraint prevents unstable and extreme solutions, while a GaussNewton technique was employed for adjusting the model resistivities with re-calculation of the sensitivity (Jacobian) matrix at each step of iteration (Loke \& Barker 1996; Loke \& Dahlin 1997). In the inversion of the data, the damping factor can be varied, and the vertical-to-horizontal flatness filter ratio adjusted according to the expected geology. In this case, data were corrected for topography before the inversion, and the vertical-to-horizontal flatness filter ratio was set to unity.

All smoothness constrained multi-layer or multi-cell inversion results in gradual transitions beween layers, 
(a)

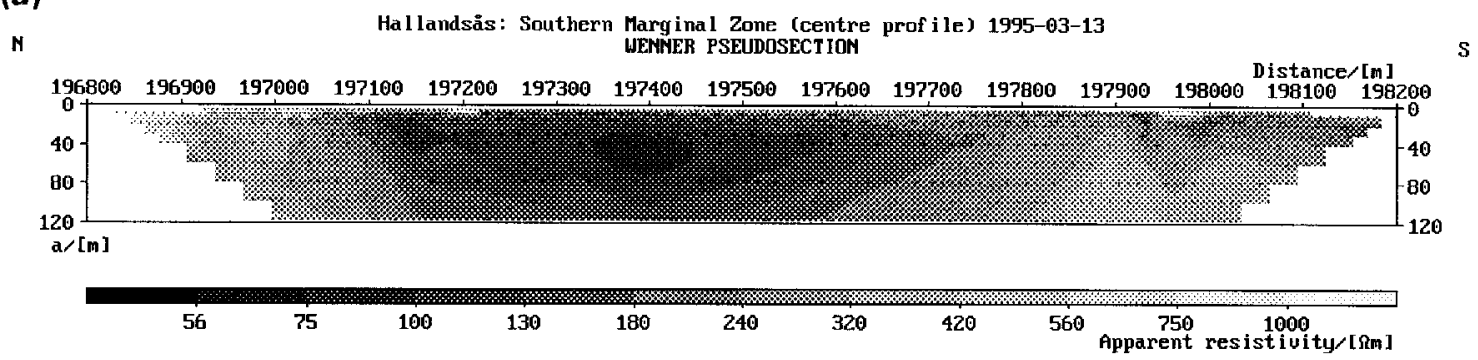

(b)

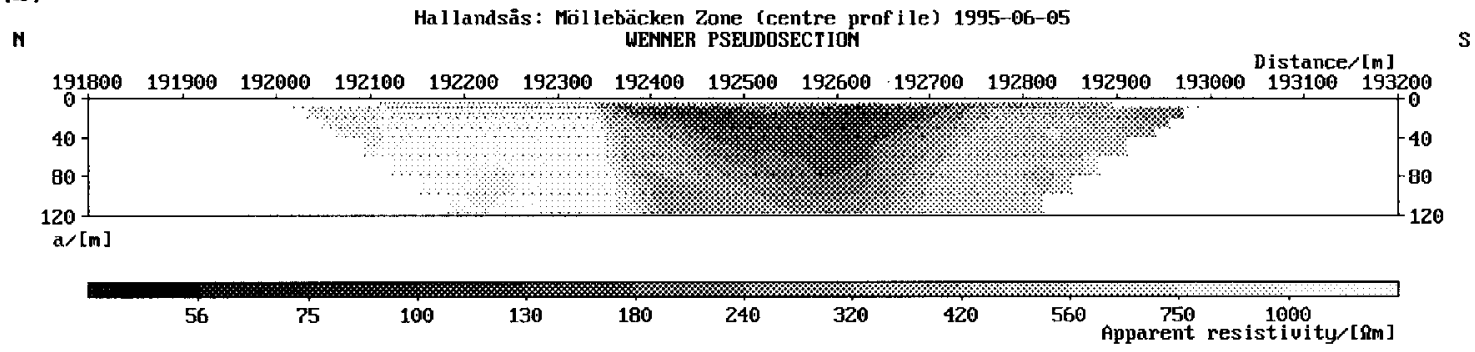

Fig. 4. Pseudosections from centre traverses: (a) Southern Marginal Zone; (b) Möllebäcken Zone. All distance co-ordinates are based on the Swedish Rail system.

even if the real geological boundaries are sharp and distinct. Furthermore, the principle of equivalence makes a range of resistivity distributions possible within certain limits, where the uncertainty increases with decreasing data quality. Also, there is an increasing integration of the properties of strata with depth, which results in decreased resolution with depth. Thus, automatic imaging can give a comprehensive overall picture of the electrical structure and variation of the subsurface, but does not provide exact information on the depths of the strata.

\section{Results}

The five traverses over each zone resulted in pseudosections with good data quality (Fig. 4), and good agreement between the parallel lines. Each section is composed of 900-1500 data points, i.e. measurements from different four-electrode combinations, depending on the length of the profile. A few electrode locations were excluded in the data acquisition due to roads and the railway, and consequently a few data points are missing in the pseudosections.

For the Southern Marginal Zone the pseudosections reveal a major zone of low resistivity around 700 metres wide (Fig. 4a), where apparent resistivities well below $100 \Omega \mathrm{m}$ are found. Only at the ends of the profile are relatively high resistivities indicated at depth. The Möllebäcken Zone (Fig. 4b) has a different character with a more narrow zone of lower resistivities flanked by high resistivities.
The interpreted depth sections from the Southern Marginal Zone show a large zone with resistivities below $100 \Omega \mathrm{m}$ in the centre of the profiles (Fig. 5a). Note that the tunnel line is indicated in the section. There is a strong depth variation in the low resistivity zone, and the zone penetrates below the planned tunnel level in places (e.g. at 197400 metres and 197700 metres). Within the low resistive zone, higher resistivities are indicated at depth in parts of the zone (e.g. at 197650 metres).

The depth sections from the Möllebäcken Zone (Fig. 5b) have a significantly different character, with a clearly defined zone of lower resistivity that is around 200 metres wide. Only within the top 10-20 metres is the zone wider. The zone is surrounded by high resistivities.

\section{Geological interpretation}

The low resistivities of the Southern Marginal Zone (Fig. 5a) clearly indicate a major zone of poor quality rock, which is almost 700 metres wide. The resistivities indicate that the zone consists of weathered crystalline rock or sedimentary rock. At the ends of the profile resistivities indicative of less weathered or unweathered material are seen, although the resistivities are low enough to indicate that the rock is fractured and water bearing despite its crystalline nature.

A $10 \mathrm{~m}$ thick layer with high resistivity is seen at the top of the sequence, and is interpreted as Quaternary deposits such as till. High resistivity regions at the 
(a)

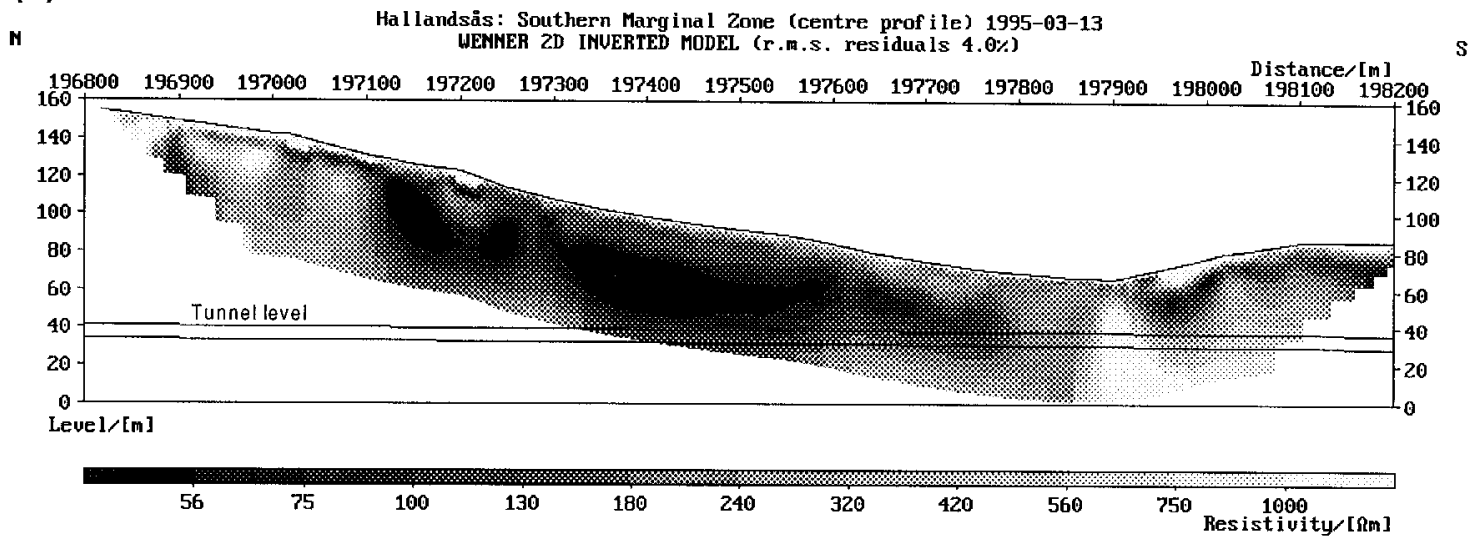

(b)

Hal landsås: Möl lebäcken Zone (centre profi ile) 1995-06-05
WENHER ZD INUERTED MODEL. (r.m.s. residuals 3.1\%)

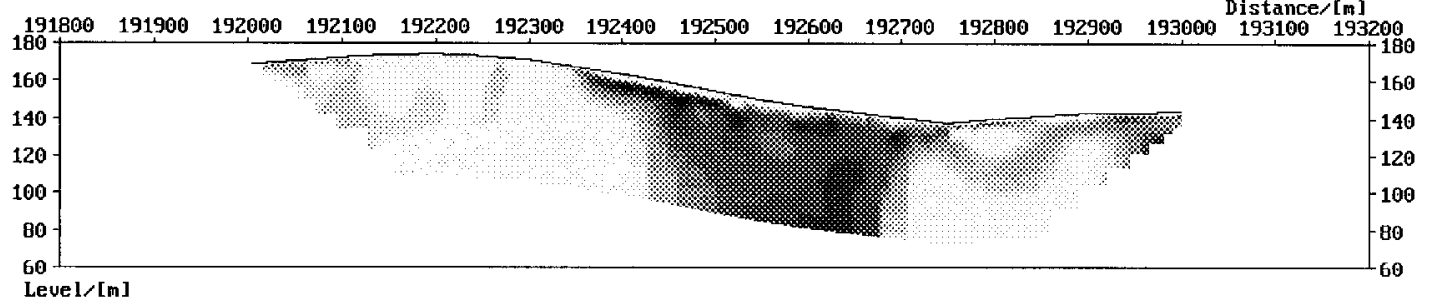

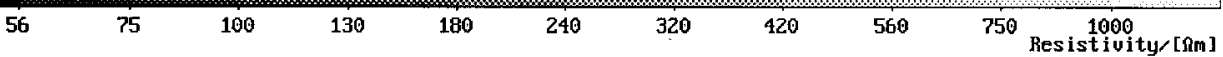

Fig. 5. Interpreted resistivity-depth sections from centre traverses: (a) Southern Marginal Zone (with position of tunnel indicated); (b) Möllebäcken Zone.

surface coincide with well drained slopes consisting of coarse grained material (e.g. at 197200 metres).

The low resistivity at the Möllebäcken Zone (Fig. 5b) indicates a rather well defined near vertical zone of fractured and/or weathered rock. The widening near surface can be interpreted as either a widening of the zone, or a small pocket of sedimentary rock, or a pocket of fine grained sedimentary soils. The high resistivities outside the zone are indicative of fresh rock.

\section{Coring and logging}

\section{S-Geobor wireline core drilling}

Two cored boreholes, KB 9501 and KB 9502, were drilled in the Southern Marginal Zone of the Hallandsås Horst. The upper parts of the two boreholes were drilled with the ODEX-method and the casing reached $39 \mathrm{~m}$ and $24 \mathrm{~m}$ below surface respectively. KB 9501 was core drilled from 39-81 m and KB 9502 from 24-60 m (Fig. 6). The positions of the boreholes as well as the core drilling intervals in the boreholes were chosen on the basis of the resistivity data and tunnel position.

The core drilling was performed with the S-Geobor system, a core drilling system based on the wireline principle. The wireline technique means that the core drilling pipes remain in the ground during the operation. This means that time-consuming and possibly damaging trip out operations are not necessary. The cores are taken out from inside the drilling pipes by wire-line lifting, giving an overall high percentage of core recovery and good quality.

The diamond-bit coring equipment $(146 \mathrm{~mm}$ in outer diameter) was in this case mounted on an updated Atlas Copco Mobile 80 drill rig. The 1.5 metre long metallic sampler has a plastic tube liner, giving cores with a $102 \mathrm{~mm}$ diameter. The inner plastic tube of the core sampler was lengthwise split in two halves before coring and held together by plastic tape, making the opening procedure very simple. This type of core drilling is particularly good for recovering cores from heterogeneous material such as soils and fractured or weak rock. 


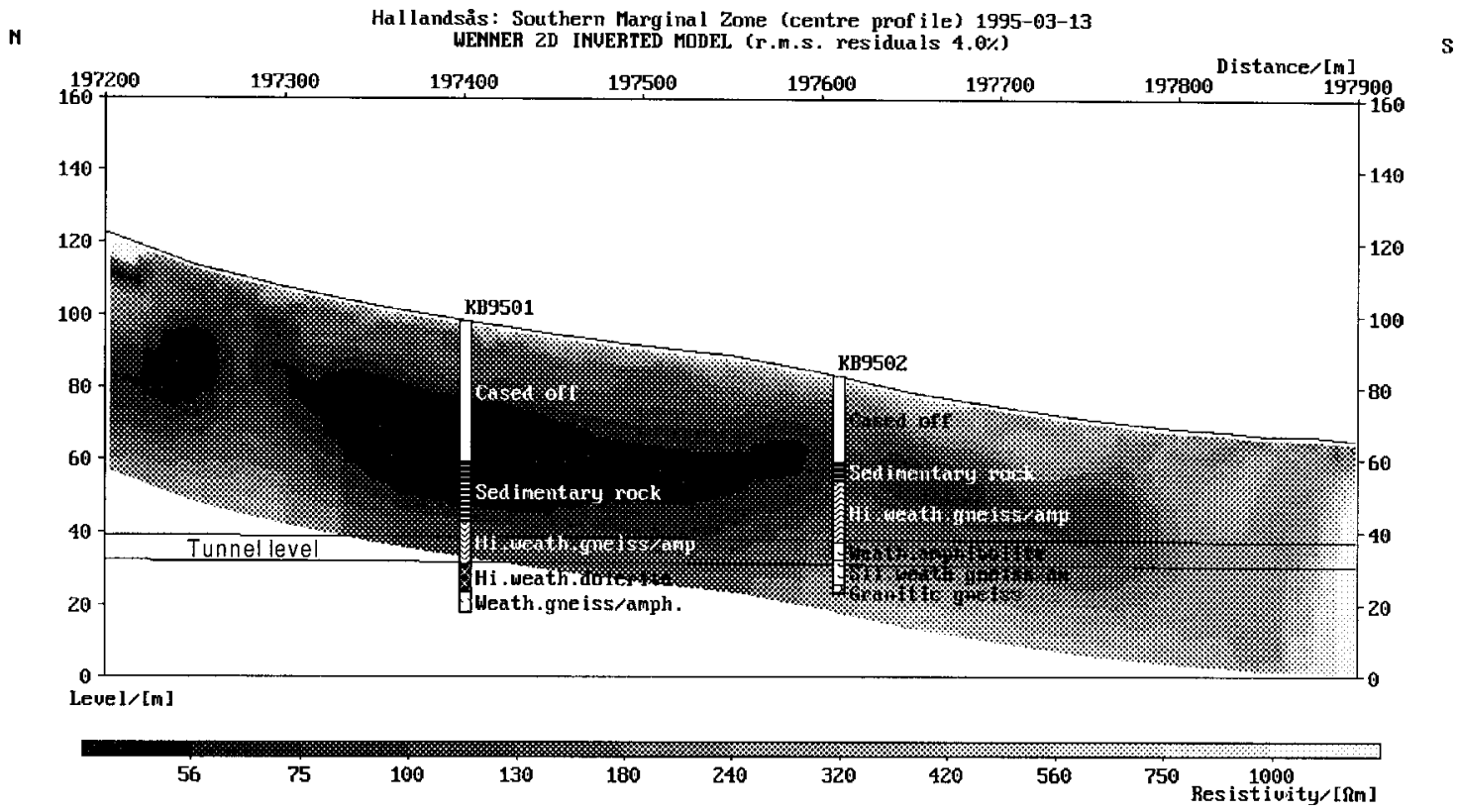

Fig. 6. Detail of interpreted resistivity-depth section from the centre profile with geological log from S-Geobor core drilling superimposed. The tunnel position is also indicated.

The results from the two core drillings show almost no core losses with a total recovery of $96 \%$ and $99 \%$ respectively. This result was very good compared to core drillings performed earlier in this tunnel project.

\section{Geological core logging}

Every $1.5 \mathrm{~m}$ long core was examined on site. Geological core logging, photo documentation, and determination of some rock mechanical properties were carried out by a site geologist. In the core examination, standard ocular engineering geological methods were used for classification of lithology, degree of weathering, induration, strength and RQD.

\section{Geophysical borehole logging}

The aim of the geophysical logging was to obtain a vertical resistivity log in the boreholes, to compare with the resistivity distribution determined from the imaging. Generally, a borehole geophysical logging program is essential, especially when dealing with borehole intervals where core loss occurs. However, (as described below) in this case there was almost no core loss, so the geophysical logging was carried out for reference and correlation purposes. A simple hand operated logging equipment was used, and measurements of the 64-inch long lateral resistivity were made every $0.5 \mathrm{~m}$.

\section{Results}

The two core sections expose sedimentary rocks from late Triassic/early Jurassic resting on weathered Precambrian rocks. Mechanically these rocks are field classified as having a material strength of 'weak rock', 'very weak rock' and 'stiff soil'. Only in the bottom parts, especially of KB 9502, is there hard rock of the normal Swedish Precambrian basement (Fig. 7).

KB 9501 consists of $7 \mathrm{~m}$ of sandstones, clays and coal from the Rhaet-liassic period and $10 \mathrm{~m}$ of red clays of the Kågeröd Formation. KB 9502 exposes some $5 \mathrm{~m}$ of sedimentary rocks of the same type. In the cased-off upper borehole parts above the core drilled interval it is likely to expect sedimentary rocks topped with some $10 \mathrm{~m}$ of glacial deposits, probably glacial till.

Both core sections confirm the upper Precambrian to be gneiss with amphibolitic parts and dolerite. The uppermost $15-20 \mathrm{~m}$ of the Precambrian consists of highly weathered rocks. In the lower parts of KB 9501 there are harder rocks of slightly-moderately weathered gneiss and amphibolite in the interval 75-79 m. KB 9502 exposes moderately-slightly weathered gneiss in the interval $46-51 \mathrm{~m}$ and unweathered to slightly weathered gneiss and granitic gneiss in the bottommost cored interval of $51-60 \mathrm{~m}$. 


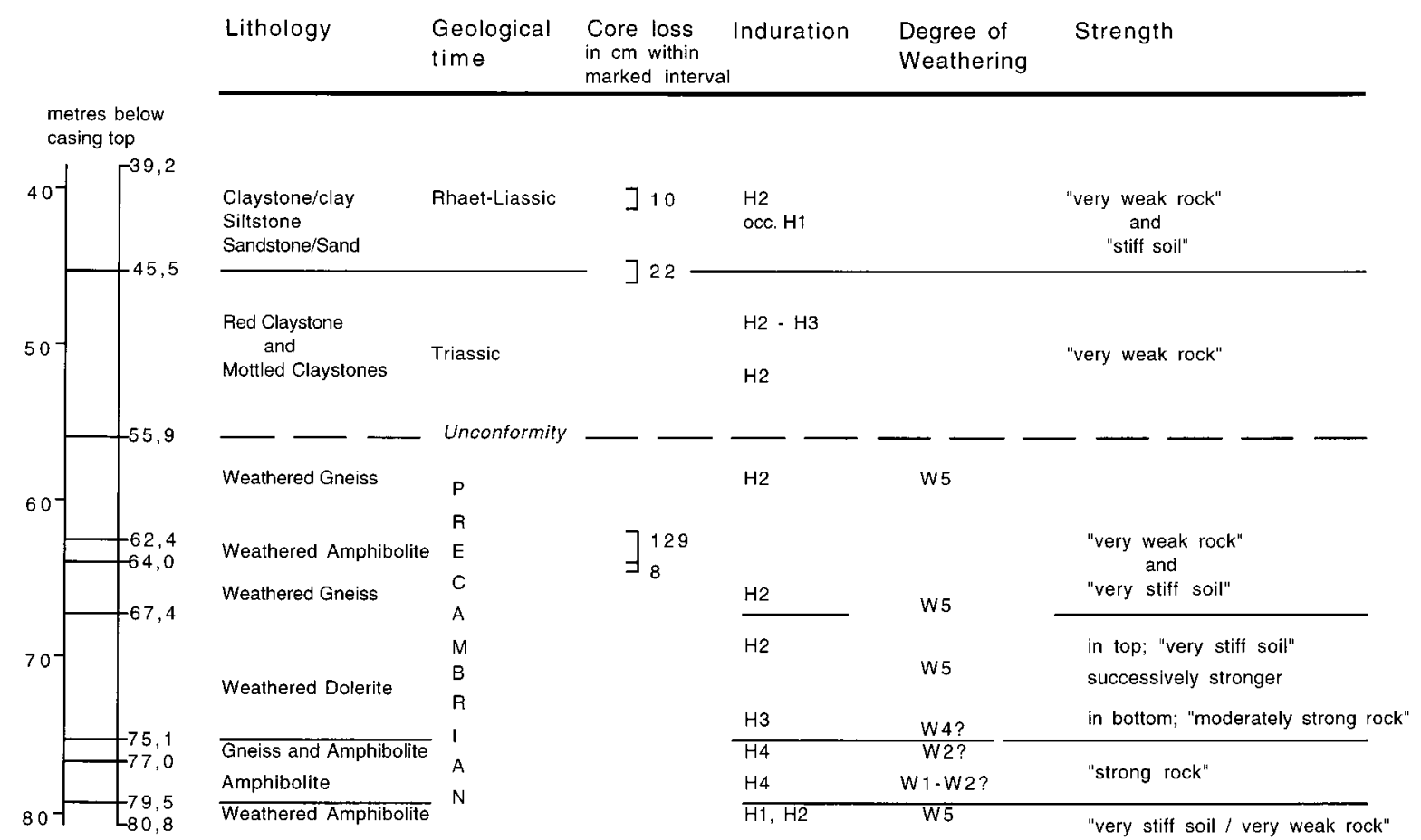

Fig. 7. Overview of classification from core from drilling KB9501, Southern Marginal Zone, Hallandsås Horst.

Finally, the borehole resistivity logging of KB 9501 reveals low resistivities of $8-68 \Omega \mathrm{m}$. If differences in resolution are taken into account, the lowest recorded resistivities in the logging may be restricted to a rather narrow zone, these values corresponding well to the values obtained by surface resistivity surveying (Fig. 8). Furthermore, the resistivity log has a close correlation to the detailed lithology as presented in Fig. 9. The low resistivity values of $25 \Omega \mathrm{m}$, belonging to the Triassic clays of the Kågeröd Formation, and the 15-20 $\Omega \mathrm{m}$ interval, belonging to a strongly weathered (and partly completely weathered) dolerite/amphibolite, are clearly recognized. Borehole KB 9501 was resistivity logged down to $72 \mathrm{~m}$ depth, whereas logging could not be carried out in Borehole KB 9502 due to collapse of the open hole.

\section{Conventional drilling at the Möllebäcken Zone}

At the Möllebäcken Zone conventional drilling confirms a highly fractured water bearing zone, where the drilling was a combination of percussion drilling (BP11 and BP22) and core drilling (KB9, EKB10 and EKB12B). Figure 10 shows the position of the boreholes and the future tunnel, and a rock quality index (Q-value) estimation based on the drilling documentation and other available data. The good match between the low resistivity zone and the low Q-values is evident. Although the depth penetration does not reach the tunnel level here, the results are in good accordance since the tectonic structures are more or less vertical. In addition, test pumping results from the percussion holes are also presented in Fig. 10. For BP22, which is drilled just outside the low resistivity zone, the transmissivity is $9.4 \times 10^{-6} \mathrm{~m}^{2} / \mathrm{s}$ and the specific capacity $24.2 \mathrm{l} / \mathrm{h} \mathrm{m}$. The result for BP11, drilled through the margin of the zone, gives a transmissivity of $1.2 \times 10^{-4} \mathrm{~m}^{2} / \mathrm{s}$ and a specific capacity of $2991 / \mathrm{h} \mathrm{m}$, which is more than a magnitude higher.

\section{Discussion and conclusions}

DC resistivity surveys provide a continuous image over the variation in rock properties of the investigated lines of Hallandsås, where parallel profiles provide similar results which clearly delineate major zones of low rock mass resistivity. The approximate extensions of the zones are shown by the inverted depth sections, and it is evident that the two zones are very different in character.

Within the Southern Marginal Zone there is a large variation in rock properties. The resistivity results are confirmed by logging and explained by the drilling, which adds precise depths and characteristics of the strata. The resistivity imaging does not show such low 


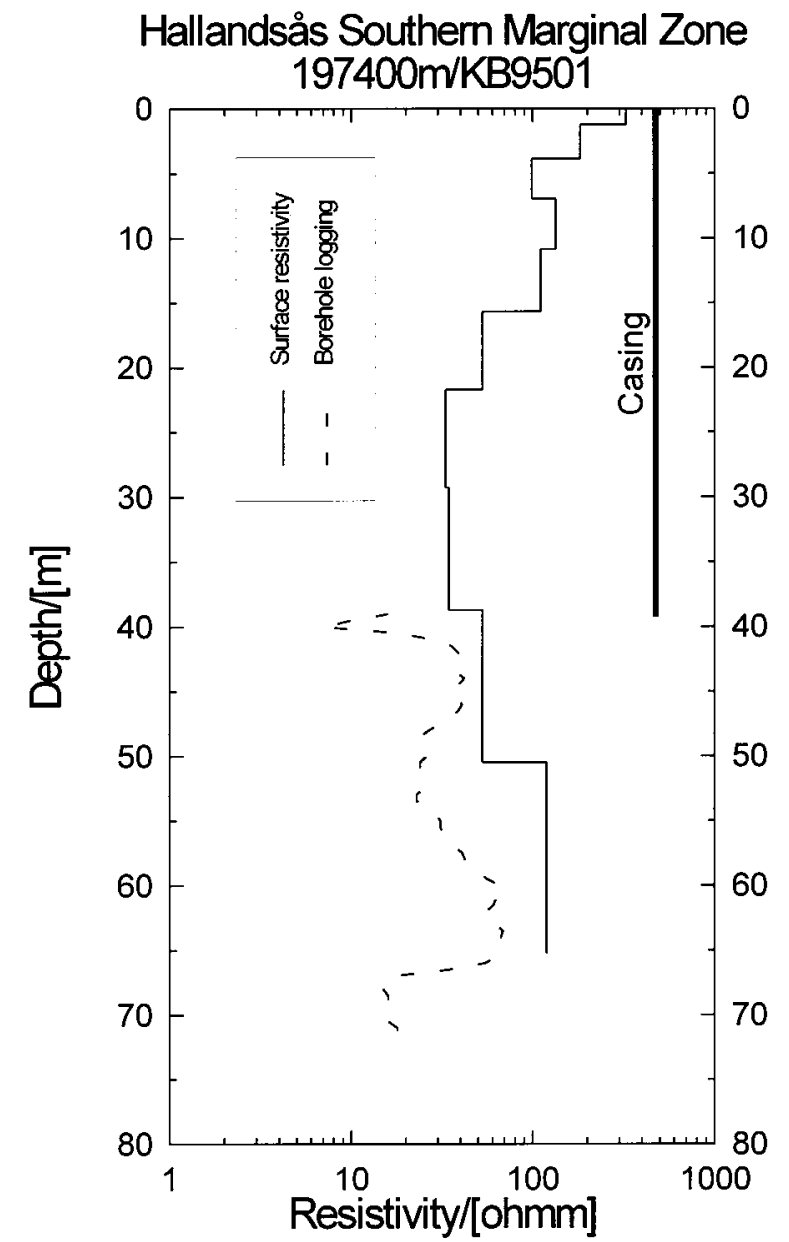

Fig. 8. Downhole resistivity log from borehole KB 9501, with inverted resistivity depth model shown for comparison.

resistivities as the geophysical logging, which is an effect of the smoothness constraint in the inversion and the volume integration that increases with depth, although the range of resistivities match each other well. The two-dimensional approximation strategy used for surveying and inversion is suitable for modelling the geological structure at the investigated sites, with a major tectonic extension more or less perpendicular to the extension of the railway tunnel.

At the Möllebäcken Zone the results do not reach as deep as the tunnel level; this would require use of longer electrode separations or a different electrode array. Nevertheless, the results delineate a major zone which is essentially vertical and seems to continue to greater depths, and drilling confirms that it persists to the tunnel level. Test pumping confirms strong variations in the hydraulic properties of the rock, that are correlated to the resistivity variation.

The wireline core drilling provided an almost complete core recovery which is remarkable in the encountered strata. Earlier conventional core drilling failed to recover any cores from the sedimentary and strongly weathered strata of the Southern Marginal Zone, i.e. the sequences which are among the most significant for tunnel pre-investigations. So, despite the fact that a number of drillings had been carried out in the zone prior to the drilling described here, including core drilling and percussion drilling, the existence of sedimentary rock in the sequence had not been shown. The value of getting a more or less continuous sample for a reliable engineering geological classification of the material is evident. It is also essential for the understanding of the geological development in the area, and fundamental for the ability to create reliable anticipation models and relevant predictions.

Geophysical borehole logging is a valuable complement to rock core classification, especially in cases where the core recovery is not complete. In addition it provides a valuable feedback for and verification of the interpretation of the surface resistivity data. In cases with drilling methods that do not provide cores, geophysical borehole logging is even more essential.

The composite investigation concept presented above was successful in providing a good overview of the variation in rock quality and geological structure. The continuous data cover minimizes the risk of overlooking important features, and a detailed engineering geological classification is provided as well as information of genetic significance. There are few, if any, alternative methods which could provide the same combination of coverage, detail and depth information at reasonable cost under these conditions. For example, electromagnetic methods suffer from disturbances from railway lines and power supplies for the buildings along parts of the lines of investigation.

Drilling can only provide point information at a high cost, and is no alternative for overview purposes. However, sampling of the formation and in situ measurements are indispensable for building a reliable engineering geological model for projects of this size, and it thus essential to place the drilling in the most representative points. The drilling technique chosen is of fundamental importance if drilling data are to be complete and unambiguous. Due to the cost of core drilling it is essential to site the boreholes at representative points, and the resistivity imaging provides an excellent basis for this. The resistivity imaging also provides a sound basis for interpolation and extrapolation between boreholes.

Acknowledgements. We wish to thank the Swedish National Rail Administration for permission to publish the data. We also want to express our appreciation for a fruitful co-operation throughout the various phases of the work to the Rail Administration, Sydkraft Consult, VBB Viak Consulting Engineers and Triumf Geophysics. Part of the work behind this paper was supported by a research grant from SGU (Swedish Geological Survey), which is gratefully acknowledged. 


\section{Penetrationrate}

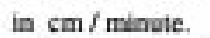

Resistivity logging, Long Normal - 64".
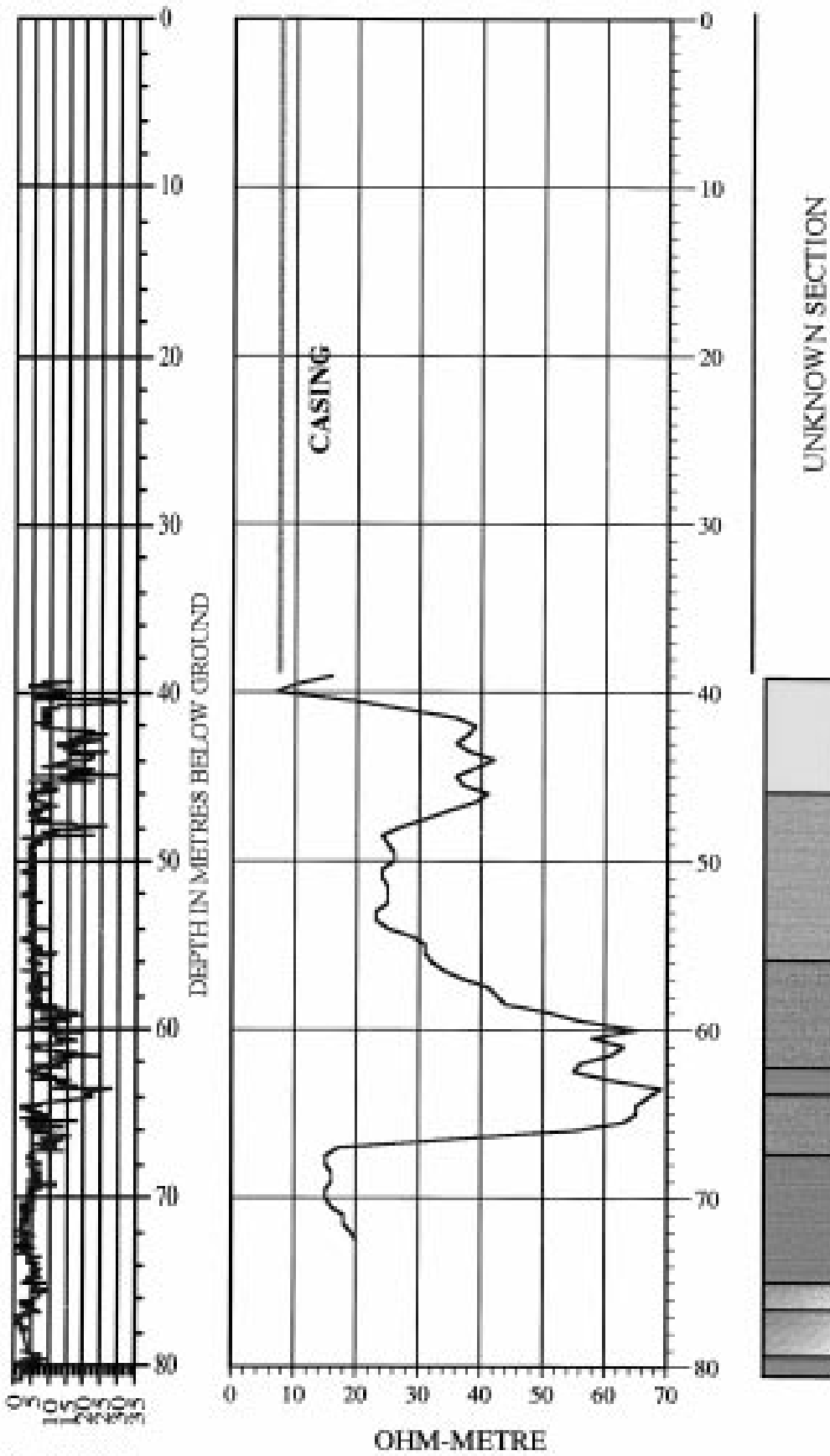

S - GBOBOR

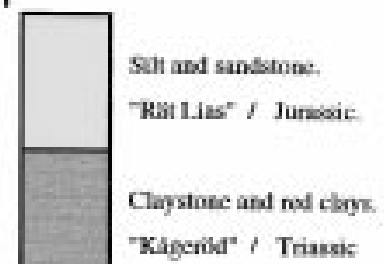

\section{L.ITHOLOGY}

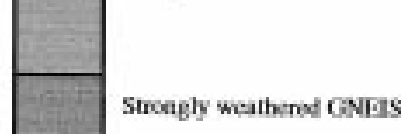

Stroagly weathernd GNFISS.

Strongly wathered

AMPHIBOL $T$ TE.

Strongly wathered GNISSS.

Strungly weathered $f \circ$

weatherat DOLERTE

Stightly werth. Gociss \& Amptid.

Shiphlly woah. Amplibolite.

Strongly wcah. Ampaibolice.

$140102 \mathrm{~mm}$

Fig. 9. Geological log from borehole KB 9501, with geophysical logging result. 


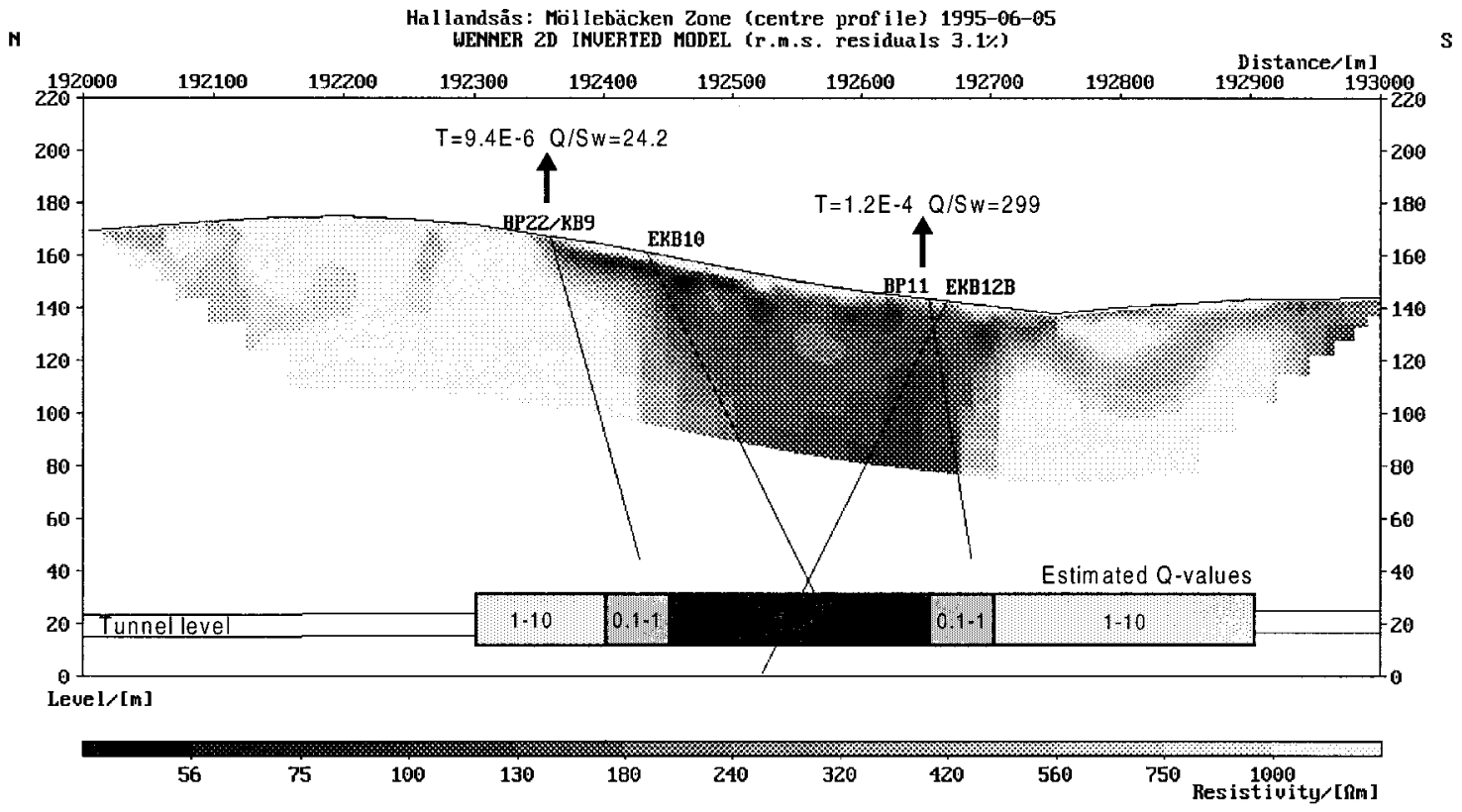

Fig. 10. Interpreted depth section from Möllebäcken zone with position of drillings and future tunnel superimposed on resistivity section from central profile. The figure also shows a rock mechanic classification at tunnel level (based on drilling results and other available data), and test pumping results ( $\mathrm{T}$, transmissivity in $\mathrm{m}^{2} / \mathrm{s} ; \mathrm{Q} / \mathrm{sw}$, specific capacity in $1 / \mathrm{h} \mathrm{m}$ ).

\section{References}

DAHLIN, T. 1993. On the Automation of Resistivity Surveying for Engineering and Environmental Applications, Dr. Thesis, ISRN LUTVDG/TVDG-1007-SE, ISBN 91-628-1032-4, Lund University.

1996. 2D resistivity surveying for environmental and engineering applications. First Break, 14, 275-283.

Griffiths, D. H., Turnbull, J. \& Olayinka, A. I. 1990. Two-dimensional resistivity mapping with a computercontrolled array. First Break, 8, 121-129.

Kunetz, G. 1966. Principles of Direct Current Resistivity Prospecting, Gebrüder Borntraeger, Berlin.

LoKe, M. H. \& BARKer, R. D. 1996. Rapid least-squares inversion of apparent resistivity pseudosections by a quasi-Newton method. Geophysical Prospecting, 44, $131-152$.

\& Dahlin, T. 1997. A combined Gauss-Newton and quasi-Newton inversion method for the inversion of apparent resistivity pseudosections. Proceedings of the $3 \mathrm{rd}$
Meeting on Environmental and Engineering Geophysics, Aarhus, Denmark, 8-11 September 1997, 139-142.

Overmeeren, R. A. van \& Ritsema, I. L. 1988. Continuous vertical electrical sounding. First Break, 6, 313-324.

PAlacky, G. J. 1987. Resistivity characteristics of geologic targets. In: NABIGHIAN, M. N. (ed.) Electromagnetic Methods in Applied Geophysics. Society of Exploration Geophysicists, Tulsa, 53-130.

Parasnis, D. S. 1986. Principles of Applied Geophysics, 4th edn, Chapman and Hall, London.

WARD, S. H. 1989. Resistivity and Induced Polarization Methods. In: WARD, S. (ed.) Investigations in Geophysics no. 5: Geotechnical and Environmental Geophysics, vol. I. Society of Exploration Geophysicists, Tulsa, 147-189.

Wikman, H. \& Bergström, J. 1987a. Beskrivning till provisoriska översiktliga berggrundskartan Malmö med en karta, Serie Ba, nr 40. Swedish Geological Survey, Uppsala.

\& Bergström, J. 1987b. Beskrivning till berggrundskartan Halmstad SV, Serie Af, nr 133. Swedish Geological Survey, Uppsala. 